Finisterra, XXXVI, 72, 2001, pp. 179-193

\title{
EVOLUÇÃO DA PAISAGEM DE MONTADO NO ALENTEJO INTERIOR AO LONGO DO SÉCULO XX: Dinâmica e incidências ambientais ${ }^{1}$
}

\author{
DENISE DE BRUM FERREIRA ${ }^{2}$
}

\begin{abstract}
Resumo - Apresenta-se o quadro geral da transformação da paisagem de montado no século XX e algumas das consequências ambientais associadas como a degradação do solo e a modificação do clima local. Salienta-se que, em vastas regiões do Alentejo interior hoje completamente abandonadas, os condicionalismos ambientais criados pela degradação do solo prevalecem sobre os factores de natureza socioeconómica na dinâmica da paisagem.
\end{abstract}

Palavras-chave: História agrária; paisagem de montado; sistema agro-silvoflorestal; erosão do solo; modificação climática.

\begin{abstract}
Evolution of THE MONTADO LANDSCAPE IN THE INNER ALENTEJo DURING THE $20^{\mathrm{TH}}$ CENTURY. DYNAMICS AND ENVIRONMENTAL CONSEQUENCES - This paper presents the general context within which the montado landscape changed in the inner Alentejo during the $20^{\text {th }}$ century as well as some of the environmental consequences, such as soil degradation and modification of the local climate. In large areas nowadays abandoned, the landscape dynamics depends more on environmental limitations created by soil degradation that on purely socio-economical factors.
\end{abstract}

Key words: Land use history; montado landscape; agroforestry; agricultural system; soil erosion; climate modification.

\section{INTRODUÇÃO}

O montado corresponde à imagem de marca da paisagem agrária do Alentejo. É um tipo de paisagem, inteiramente construído, em que todos os traços se devem à história agrária e ao trabalho humano que transformaram a brenha mediterrânea. Ao longo dos séculos, o ecossistema mediterrâneo original foi simplificado na sua estrutura e biodiversidade, e transformado num sistema de uso agro-silvo-pastoral extensivo associado a grande exploração fundiária.

\footnotetext{
1 Parte da investigação relativa à sintese apresentada neste artigo foi desenvolvida no projecto Dinâmica da transformação da paisagem agrária nos concelhos de Moura e de Barrancos (1890-1995) (PRAXIS XXI 2/2.1/CHS/864/95) financiado pela Fundação da Ciência e Tecnologia e o FEDER.

2 Investigadora do Centro de Estudos Geográficos e Professora Associada da Universidade de Lisboa. E-mail : denise.ferreira@ceg.ul.pt
} 
Paisagem e sistema agrícola estavam na origem intimamente associados. A paisagem vegetal criada caracteriza-se por um uso agrícola e/ou pastoril em sob-coberto de um estrato arbóreo esparso, com densidade variável, constituído por azinheiras ou sobreiros aos quais se juntam por vezes oliveiras. Os elementos interdependentes que constituem o montado estruturam-se em vários níveis : a cobertura arbórea, as pastagens, as culturas extensivas baseadas nos cereais, os pousios de duração variável (entre dois e dez anos) dando origem, periodicamente, a um estrato herbáceo ou arbustivo (os matos) que servem de pasto aos animais (ovino, caprino, porcino e bovino). Associado ao sistema de produção do montado está ligado também um povoamento rural concentrado nos montes e em compactas aldeias. Tomando em conta a combinação de todos estes elementos, nasce uma grande heterogeneidade de paisagem possível e também de estruturas produtivas. O montado dá origem não a uma, mas a várias unidades de paisagem marcadas por uma elevada diversidade em função da densidade das árvores e das marcas da ocupação do solo passada e actual. Apresentam uma dinâmica evolutiva complexa, testemunho das alterações sucessivas mais duradouras do sistema agrícola ao qual foram associadas e dos respectivos impactes ambientais destes sistemas sobrepostos no tempo. Apesar de uma destruição já antiga, os montados ocupam ainda hoje uma vasta área na Península Ibérica. No sentido lato, trata-se de mais de 2,5 milhões de hectares, $80 \%$ dos quais em Espanha (CABO Alonso, 1998), desde a parte meridional da província de Salamanca, e Estremadura até à Andaluzia ocidental, e $20 \%$ em Portugal, sobretudo no Alentejo, mas também na Beira Baixa.

O presente artigo mostra os traços gerais da dinâmica da evolução da paisagem agrária no Alentejo interior onde domina o montado de azinho, em função da história agrária e dos impactes ambientais associados à sua transformação no último século. Para perceber as principais características actuais das unidades da paisagem agrária do Alentejo associadas ao sistema de montado, o impacte ambiental da evolução sofrida, ele próprio indutor da transformação da paisagem, é necessário considerar simultâneamente os factores históricos que presidiram à sua evolução e os factores físicos regionais condicionantes, essencialmente o clima e os solos.

\section{A TRANSFORMAÇÃO DA PAISAGEM DE MONTADO}

\section{Os primórdios}

A origem do montado encontra-se ainda sujeita a discussão mas é sem dúvida bastante antiga. Segundo Silbert (1966) e Cabo Alonso (1998), na origem da constituição do montado ibérico podemos evocar a forma como se efectuou a Reconquista e que veio condicionar o tipo de propriedade e de exploração agrárias. Na génese e na expansão da paisagem de montado deve ser referida também a importância que teve o deslocamento sazonal do gado 
ovino tanto em Espanha (transumância controlada pelo Conselho da Mesta desde a Idade Média até 1836), como em Portugal, entre a Cordilheira Central (agostadeira) e o Alentejo (invernadeira).

Um quadro bastante realista da economia, da estrutura agrária e da paisagem da Beira Baixa e do Alentejo no início do século XIX foi apresentado por SiLbert (1966) e esse quadro permaneceu em grande parte válido até às grandes transformações da paisagem agrária do fim do século XIX. Estas transformações são parcialmente retratadas nas cartas agrícolas de G. A. Pery, levantadas nos anos 1880 e 1890 na região alentejana, bem como nas respectivas memórias estatísticas. Podemos considerar que os anos 1880 marcam o desaparecimento acelerado da estrutura económica do Antigo Regime que se traduz por uma modificação radical da paisagem rural do Alentejo. O recuo dos maninhos e da charneca (brenha mediterrânea), os arroteamentos, as novas técnicas culturais, o progresso do caminho de ferro, a densificação da rede de estradas, as mudanças profundas verificadas na situação demográfica do Alentejo, as primeiras leis proteccionistas para as culturas cerealíferas foram factores decisivos na constituição de um montado cultivado ao lado do montado tradicional onde primava a presença do gado. Em consequência, na transição dos séculos XIX e XX, a evolução da área do montado foi nítida no Alentejo: 370 000 ha de sobreiros e azinheiras em 1867 e 868850 ha em 1902 (VIEIRA, 1991).

Assim, podemos aceitar a ideia que numerosos montados actuais são relativamente recentes: datam de há um século ou menos. Os exemplares de azinhais mais antigos, pluricentenários, encontram-se no Alentejo interior onde a criação de gado se manteve ao longo dos séculos nos concelhos fronteiriços de Mourão, Moura, nas serras de Barrancos e de Serpa; em primeiro lugar foi o gado ovino e, a seguir à desvalorização do mercado da lã, o gado porcino, que melhor aproveitava a lande e a bolota do montado, na criação de montanheira; esta, por sua vez, foi abandonada em meados do século XX, após o aparecimento da peste suína africana no Alentejo.

\section{As transformações do montado no século $\mathrm{XX}$}

As transformações processaram-se de modo descontínuo, pautando as fases de colonização agrária do Alentejo e a sucessão dos sistemas de produção que nele se praticaram. O balanço no século XX aponta para uma transformação profunda do uso e da estrutura do montado, a intensificação da cerealicultura mecanizada levando à destruição do estrato arbóreo ou à substituição do montado por sistemas agrários economicamente mais compensadores após o abandono da criação dos porcos de montanheira. Acentuaram-se assim os desequilíbrios ambientais nos montados pela influência de toda uma série de pressões exercidas sobre os três vertices do sistema produtivo : as árvores, as culturas arvenses e as pastagens.

Todavia, o que torna confusa a identificação clara da relação dos problemas ambientais no Alentejo com a dinâmica da transformação do montado é a 
permanência de uma estrutura social complexa e a sua ligação com a repartição da propriedade fundiária que não tiveram o mesmo ritmo de evolução que a paisagem agrária. Muitos arcaísmos penetraram profundamente no século XX , tais como privilégios antigos e servidões associados que resistiram à Revolução Liberal; os contratos e os usos que ligam o dono da terra e os que realmente a exploram; o modo de arrendamento; o direito ou não de cultivar a terra durante um período variável previamente fixado, de retirar proveito das árvores, de deixar pastar o gado; o direito de limpar o mato, de fazer queimadas; a existência de uma renda muitas vezes paga em cereais e não em dinheiro; as redistribuições periódicas de terras. Estes costumes denunciam um emaranhado de direitos de propriedade e de permissões de difícil dissolução ao longo do século XX que ditou o uso do montado e a permanência de sistemas agrários ultrapassados que deixaram marcas indeléveis na paisagem. Os interesses, só por acaso convergentes, dos diferentes intervenientes na exploração efectiva da terra numa mesma parcela ajudaram aqui a manter o sistema tradicional de uso do montado, além a transformar lentamente a sua estrutura, e outras vezes a provocar fases de rupturas rápidas na paisagem alentejana durante o último século.

\section{O nascimento da paisagem actual}

Os motores das transformações da paisagem agrária do Alentejo foram evocados num artigo anterior publicado nesta revista (FERREIRA, 1992). Será feita aqui uma síntese sucinta que permite seguir o quadro da evolução traçado na figura 1, o qual só pode ser interpretado globalmente.

A paisagem actual resultante da transformação do montado no último século comporta na sua tipologia duas subséries de degradação e diversas substituições que romperam o equilíbrio do sistema, acelerando a sua fragilização ou mesmo o seu desaparecimento.

\subsection{As modificações resultantes da intensificação do uso do montado}

A primeira subsérie de degradação resulta do incremento da antropização que conduziu à eliminação parcial ou total das árvores. Foi sublinhada na figura 1 a importância de três fases de pressão levando ao alastramento do montado cultivado na dependência de políticas agrárias proteccionistas para a produção nacional de cereais, de factores socioeconómicos e técnicos. Foram no princípio do século a influência da Lei dos Cereais de Elvino de Brito, a Campanha do Trigo entre 1929 e 1935 com o prolongamento do seu efeito até o fim da 2. ${ }^{a}$ Guerra Mundial e, finalmente, a aplicação da Reforma Agrária entre 1975 e 1979. A mais antiga causa de supressão das árvores foi o uso da lenha para a madeira e a carvoaria e, as mais recentes, na primeira metade do século XX sobretudo, a marginalização do papel das azinheiras em consequência da peste suína e do alastramento da lavra para a cerealicultura mecanizada. Neste 


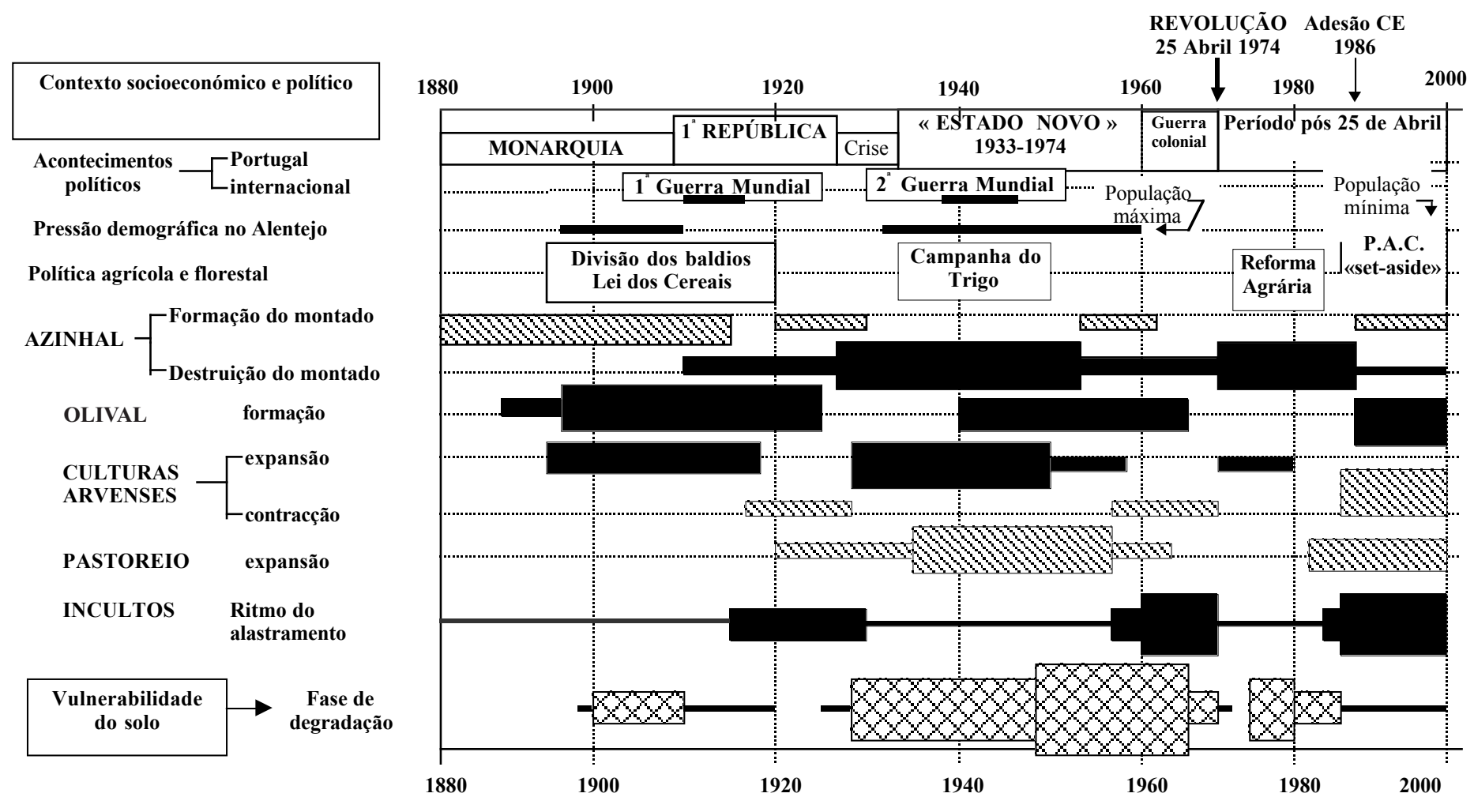

Fig. 1 - Sinopse sucinta do contexto socioeconómico e político da transformação da paisagem de montado no Alentejo interior durante o século XX (adaptado de FERrEIRA, 2000, (c) John Wiley \& Sons). As barras são proporcionais à intensidade da mudança.

FIG. 1 - Synopsis of the socio-economical and politic context of the transformation of the montado's landscape during the $20^{\text {th }}$ century (adapted version from FerReIRA, 2000, () John Wiley \& Sons). The thickness of the bars is proportional to the changes. 
último caso nasceu uma paisagem agrícola aberta de cerealicultura intensiva que alterou profundamente ou substituiu integralmente o sistema de montado. Tal foi o caso da região de Beja e de Serpa onde surgiu a partir dos anos 1930 uma nova paisagem agrícola, substituindo os matos e os montados dominantes no princípio do século $\mathrm{XX}$ nos barros com alto potencial produtivo mas de difícil maneio sem os meios técnicos adequados. A Carta Agrícola e Florestal levantada nos anos 1950 pelo Serviço de Reconhecimento e de Ordenamento Agrário dá conta da amplitude da mudança em relação à paisagem retratada pela Carta Agrícola de G. A. Pery do fim do século XIX. No espaço de cinquenta anos, a charneca tinha praticamente desaparecido da paisagem, a superfície lavrada tinha duplicado e a do montado tinha sido quase dividida por dois (FEIO,1998).

\subsection{As modificações resultantes da diminuição da pressão antrópica}

A década de 60 do último século marca o início de uma mudança socioeconómica e demográfica profunda no País, acelerando o abandono das actividades agrícolas e o despovoamento das regióes rurais. Matos invasores reapareceram nas pastagens, nos pousios longos, arborizados ou não, mais ou menos altos e densos, e de riqueza florística muito variável. A revitalização da biodiversidade é dependente das funções às quais foi ligado o montado (montado cultivado ou montado pastoril), da intensidade e do tempo do uso nos períodos anteriores induzindo um desequilíbrio ambiental mais ou menos acentuado, e do tempo de abandono (FERREIRA, 1999a). A paisagem ligada aos incultos pode ir do matorral mediterrâneo secundário em vias de estratificação (exemplos numerosos na Contenda de Moura depois de cinquanta anos de abandono voluntário pelos Serviços Florestais da terra exaurida) até ao mato de composição quase monospecífica (caso dos estevais da Serra de Serpa e de Mértola). A sombra oferecida pelas árvores varia com a densidade; à medida que diminui o número de copas no montado, os estratos inferiores são invadidos por espécies cada vez mais heliófilas.

Nos últimos vinte anos, a tendência para o crescimento da área de montado abandonado acelerou-se com o êxodo rural e a política de «set-aside» preconizada pelas sucessivas PAC depois da entrada de Portugal na Comunidade Europeia em 1986; novos incultos nasceram da redução da área dedicada à agricultura de sequeiro. As reservas de caça multiplicaram-se. A rarefacção dos pastores, o encarecimento da mão-de-obra e a necessidade de controlar a carga animal das pastagens num contexto de profunda carência de água e de solo conduziram também a uma modificação da prática pecuária. Estas diversas evoluções tiveram como consequência o alastramento do emparcelamento com recurso a vedações de arame farpado, custeadas em grande parte por subsídios comunitários. A característica dominante de largos espaços abertos entre as azinheiras que faziam o encanto da paisagem alentejana perdeu-se. Mesmo os caminhos de servidão pública, ancestrais, são actualmente vedados 
por cancelas que, na melhor das hipóteses, o viajante é convidado a abrir e fechar.

\subsection{As substituições do sistema tradicional do montado}

Os montados já não são tão contínuos e densos como outrora. A monocultura dos cereais suprimiu por completo largas manchas no espaço de vinte anos no momento da implantação da Campanha do Trigo. Em muitas áreas do Alentejo, a paisagem de montado constituiu-se de par com os olivais. Nos locais onde as condições edáficas o permitiram, os olivais expandiram-se. É o caso da região de Moura, onde se constituiu muito cedo a maior mancha contínua de olivais do País, entre o final do século XIX e os anos 1960, ocupando sobretudo os solos carbonatados da região. A tendência actual da PAC é muito favorável à subs-tituição do sistema de montado e dos sequeiros pelo olival e pela vinha (parte dos quais irrigados).

Outros aproveitamentos do solo ocupam agora uma área suficiente para mudar completamente o aspecto tradicional da paisagem alentejana. É o caso dos eucaliptais no Alentejo litoral que competem com os sobreirais, e no interior, na Serra de Ossa e de Nisa. É o caso também da reflorestação maciça em pinheiro manso que está a ser levada a cabo no Alentejo interior (concelhos de Mértola, de Serpa). O recurso às espécies de crescimento rápido aparece como uma solução convidativa porque permite uma rentabilidade a curto prazo e favorece o absentismo dos proprietários. Percebe-se que o repovoamento dos incultos com azinheiras tenha tido até agora um sucesso muito limitado. A meta dos 20000 ha de plantação prevista pelo Plano de Acção Florestal não foi ainda atingida, apesar de subsídios substanciais durante os primeiros vinte anos, iguais aos oferecidos para os sobreiros.

A economia do sistema tradicional do montado não foi revitalizada pela PAC e dificilmente a paisagem agrária associada se manterá nas condições actuais. Segundo Feio (1998, p 101), «o valor do montado de azinho passou a ser recordação saudosa e o amor por este fóssil económico é partilhado pelos ecologistas e por alguns funcionários florestais porque tem remuneração independente dos resultados económicos, o que facilita fantasias». Foram efectivamente estes os objectivos prosseguidos pelos modelos produtivistas que fizeram evoluir a paisagem do montado ao longo do século XX. Sem o sustento produtivo assegurado, a paisagem de montado desvaloriza-se e tende a desaparecer. As fotografias áreas correspondentes ao voo encomendado em 1995 pela Direcção Geral das Florestas e o CNIG (Centro Nacional de Informação Geográfica) dão claras provas desse facto. Hoje o alastramento dos matos é o traço mais visível do abandono e da marginalização crescente das regiões rurais do Alentejo interior.

Podemos considerar os montados abandonados e os incultos como uma forma de adaptação à conjuntura socioeconómica do momento e nada impede pensar que no futuro, em condições menos adversas, não possa haver uma 
regressão dos matos. A entrada em funcionamento da barragem do Alqueva continuará sem dúvida a fazer evoluir a paisagem alentejana. No imediato, é a criação de uma vasta albufeira de $250 \mathrm{~km}^{2}$ que irá modificar completamente a paisagem do Alentejo interior; num segundo tempo, será a introdução de perímetros de culturas irrigadas, onde as condições edáficas o permitirem e, sem dúvida, a criação de áreas de vilegiatura e de lazer nas imediações da albufeira que tenderão a inverter o vazio humano ao qual é votado o Alentejo interior, dando uma alternativa talvez viável à função agrícola periclitante do montado. A apropriação urbana dos montados e dos seus incultos tornou-se aliás um facto já nos anos noventa do século XX. A exploração cinegética dos matos e montados abandonados nas imensas reservas constituídas nos últimos vinte anos, bem gerida, oferece também uma interessante possibilidade de tirar proveito de um recurso natural, favorecendo a sua própria conservação.

\section{RESILIÊNCIA DA PAISAGEM DE MONTADO E MUDANÇA AMBIENTAL}

\section{O problema da resiliência da paisagem}

A questão que podemos discutir face à evolução evocada diz respeito à resiliência da paisagem de montado de azinho, ou seja, a capacidade que tem a paisagem do montado para recuperar um novo equilíbrio dinâmico (mesmo precário) depois de ter sofrido transformações profundas durante o último século. A questão tem sentido no pressuposto de existir uma vontade política de manter vestígios de uma paisagem cultural típica do Sul de Portugal, memória de uma história agrária talvez tão rica de significado como a da paisagem do Alto Douro, que acaba de ser declarada Património da Humanidade; mas, ao invês desta, já não é uma paisagem viva, porque desligada agora do sistema produtivo tradicional que a sustentava (portanto à procura de uma viabilidade económica), e muitas vezes apresentando um estado de degradação avançado.

\section{Os factores limitantes da recuperação ambiental}

\subsection{O clima regional}

Entre os factores naturais mais limitantes da recuperação ambiental figura sem dúvida o clima, não só pelas suas características mediterrâneas com degradação continental muito rápida para o interior, mas também porque condiciona os processos de pedogénese, de produtividade em biomassa e de regeneração. O clima comporta duas estações desfavoráveis à produção vegetal : o Verão, quente a muito quente e seco, e o Inverno, húmido e frio no Alentejo interior. A precipitação tem uma grande variabilidade intra e interanual. Estas características determinam na vegetação o predomínio de estratégias de adaptação dirigidas sobretudo para suportar as condições desfavoráveis no Verão. É a 
esclerofilia que se manifesta num grande número de espécies lenhosas, tanto arbóreas como arbustivas, e no ciclo anual de muitas espécies das pastagens (terófitas). A sobrevivência é assegurada por um desenvolvido sistema de raízes capaz de bombear verticalmente a água dos horizontes mais profundos do solo, e lateralmente, quase superficialmente, aproveitando ao máximo a água das primeiras dezenas de centímetros de solo. A resiliência da vegetação, mesmo das árvores mais preparadas para resistir à aridez, depende assim da existência de um solo suficientemente desenvolvido para ter uma reserva de água que diminua o stress hídrico provocado pela irregularidade da chuva.

\subsection{Vagas erosivas e transformação do montado no século $X X$}

É possível estabelecer a relação entre algumas vagas erosivas severas e as fases de transformação profunda do montado durante o último século. Na sinopse dos acontecimentos socioeconómicos e políticos do século XX apresentada na figura 1, diferentes fases de sobre-exploração dos recursos do solo foram realçadas. Representam rupturas ambientais importantes. A primeira marca-se pelo desmatamento da charneca para criação de novos montados e pelo alastramento das terras de culturas e de pasto em sob-coberto entre 1899 e 1918 em consequência da aplicação da Lei dos Cereais de Elvino de Brito. É uma fase curta, de arroteias realizadas penosamente à mão, com alvião e foice roçadoura e com recurso às queimadas, com o trabalho da terra feito a seguir com tracção animal e alfaias de mobilização muito superficial. Apesar de se tratar de terras novas, com um potencial de fertilidade máximo, não foi nesta fase, não obstante o efeito das queimadas, que a erosão do solo deve ter sido a mais acentuada.

A segunda fase de colonização intensa do Alentejo e da transformação acelerada do uso e da estrutura do montado data do tempo da «Campanha do Trigo», incitada com grandes meios de propaganda entre 1929 e 1938 para transformar o Alentejo no celeiro de Portugal. É uma fase da política socioeconómica do Estado Novo que foi intensamente estudada (RosAs, 1994) e que deixou um volume ímpar de documentos sobre a profunda transformação da paisagem agrária desta região; transformação que continuou pelo menos até ao fim da Segunda Guerra Mundial. A Campanha do Trigo é amplamente reconhecida na literatura como tendo sido a fase mais gravosa para a degradação do solo e do montado. De facto, potencialmente, deve ter sido o caso. A introdução da lavra mecanizada profunda não só permitiu um alastramento muito rápido do uso agrícola do solo e da sua intensificação até terras cada vez mais marginais (terras galegas), como obrigou a um derrube maciço das árvores, podendo ir até à supressão total do estrato arbóreo nas terras mais férteis (exemplo, na região de Évora, nos barros de Beja e nas terras fortes de caliços). A lavra mecanizada suprimiu a necessidade de ter gado para trabalhar a terra e assim a de manter folhas em pousio ou em pastos. As rotações das culturas foram aceleradas em solos que já não podiam reconstituir o seu potencial de matéria 
orgânica fornecido inicialmente pelo estrato arbóreo, os pousios e o gado. O problema da perda de rendimento agrícola foi em grande parte e momentâneamente resolvido com a importação maciça e crescente de adubos químicos.

Finalmente, a aplicação da Reforma Agrária entre 1975 e 1979 contribuiu de novo para reforçar o aproveitamento cerealífero do montado, parte do qual tinha sido votado aos matos ou pousios longos em consequência da emigração dos anos 1960 e da Guerra Colonial. Foi retomado o desmatamento das terras abandonadas que muitas vezes já não tinham capacidade para suportar culturas. Esta nova fase de intensificação do uso do montado implicando, de novo, o derrube das árvores, foi curta mas bastante agressiva, com uso de maquinaria pesada, como, pela primeira vez, os caterpillars, para a conquista rápida de terras agrícolas, e com a incorporação de grandes quantidades de adubos químicos. O seu peso na degradação do solo está ainda por determinar. Sabemos que os anos 1978 e 1979 que marcam o fim desta nova investida da intensificação cerealífera, particularmente chuvosos no Inverno, tiveram uma erosividade importante no Alentejo (Roxo, 1994).

As causas mais evocadas para explicar a variabilidade espacial da degradação do solo no Alentejo são assim as práticas culturais gravosas introduzidas no montado cultivado e o sobrepastoreio. Todavia, devemos também evocar o papel do clima e da sua variabilidade no século XX. O tipo e a frequência dos processos de erosão do solo apresentaram uma grande variabilidade e conduziram a mudanças no padrão espacial e na magnitude da degradação do solo. Quatro escalas de variabilidade devem ser consideradas no intuito de perceber como a erosão hídrica do solo e o risco climático associado à transformação do sistema do montado conduziram a uma degradação biofísica extrema no Alentejo interior ao ponto de se falar em «desertificação»: a escala do evento chuvoso, a distribuição sazonal da chuva, as fases de seca ou de excesso de chuva e a tendência secular. Estas quatro escalas, de modo separado ou em sinergia, põem à prova o equilíbrio do complexo solo-vegetação.

A evolução do clima do Alentejo no século XX foi marcada por sucessões de secas e de fortes precipitações durante a estação chuvosa, entre Outubro e Maio (Maheras et al., 1994; Ventura, 1994). Durante a Campanha do Trigo e a Segunda Guerra Mundial, nos anos 30 e 40 do século passado, a agricultura foi intensificada mesmo nas terras marginais. É nestas duas décadas de intensas transformações do uso do montado que são habitualmente apontadas as fases de maior degradação do solo. Todavia, a perda de solo por erosão hídrica deve ter sido máxima não durante estas duas décadas de cariz seco mas durante os anos 1960. A década de 1960 foi marcada por longas sequências de chuva abundantes, por uma maior frequência de chuvadas de forte intensidade, e pela deriva do máximo pluviométrico para os meses de Outono, momento do ano de lavra generalizada no Alentejo.

Tomando o exemplo de Évora e o período 1940-1992, a década de 1960 inclui $31 \%$ dos 276 eventos com mais de $25 \mathrm{~mm}$ de chuva, e $23 \%$ dos de mais de $50 \mathrm{~mm}$. Foram registadas fortes intensidades: $29 \%$ dos eventos com período 
de retorno entre 20 e 50 anos, e ainda $50 \%$ dos eventos com períodos de retorno de mais de 50 anos pertencem a esta década particular (BRANDÃo et al., 1999; Fragoso et al., 2000). É nos outonos chuvosos que nas terras lavradas se verificam mais de dois terços da perda anual de solo. Desde 1980, a chuva do fim do Inverno e da Primavera tornou-se muito deficiente. Secas invernais apresentaram paroxismos entre 1980 e 1983 e na primeira metade dos anos 1990. Isso não impediu que tenha continuado a existir uma frequência cada vez maior de sequências chuvosas intensas durante o Outono, enquanto a estação chuvosa se reduzia ao período entre Outubro e Fevereiro.

A maior concentração da chuva no Outono e no Inverno verifica-se desde 1963 (Mendes et al., 1993). Os dias chuvosos na Primavera tornaram-se muito escassos, sobretudo em Março. Assim o stress hídrico próprio do Verão mediterrâneo começa mais cedo (FERREIRA, 1995). Desde 1963, a deficiência hídrica generalizada no Alentejo constitui uma nova limitação à boa conservação das pastagens no montado e à criação do gado. Para fazer face a esta situação de carência de água para o gado, milhares de pequenas barragens em terra, servindo de bebedouros, foram construídos. As culturas de Primavera tornaram-se muito pouco rentáveis sem irrigação e a sua área diminuiu drasticamente. A carência generalizada em água do Alentejo interior, cada vez mais cedo no ano, devido ao duplo problema de uma seca recorrente na Primavera e de uma procura acrescida, levou à sobreexploração das águas subterrâneas e à deterioração da sua qualidade.

\subsection{Retroacções entre o clima e a degradação do solo}

As secas recorrentes na segunda parte do século XX deixaram marcas na paisagem do Alentejo interior. Em primeiro lugar, desde os anos 1960 foi a falta de chuva na Primavera que alargou a estação seca típica do clima mediterrâneo e, a partir dos anos 1980, com uma maior variabilidade da chuva invernal, houve uma amplificação da intensidade da secura (FERREIRA, 1999b). Se globalmente, à escala do ano, a quantidade de chuva se mantém praticamente a mesma, a aridez climática aumentou no Alentejo. Mesmo as azinheiras, normalmente resistentes ao stress hídrico, não têm regeneração possível nos solos de xisto mais delgados. Vastas áreas de incultos anormalmente pobres floristicamente, sem árvores ou com árvores a morrer de stress hídrico, de doenças e de falta de tratamentos, constituem actualmente uma parte substancial da paisagem agrária do Alentejo interior. No limite, com o desaparecimento das árvores e do próprio solo, os incultos são constituídos por estevais muito pouco exigentes em água, insensíveis à textura do solo, suportando o fogo e o aumento da aridez à superfície do rególito. As terras submetidas ao sobrepastoreio, com solo compactado pelo pisoteio, apresentam largas clareiras de solo muito dificilmente colonizadas por tufos de mato rasteiro onde o sargaço domina. A destruição do solo até ao substrato geológico, impermeável no caso dos xistos, verifica-se em $70 \%$ da área da Bacia do Guadiana. Sem uma reserva hídrica 
suficiente nos litossolos, a estação seca começando mais cedo, a biomassa produzida torna-se mais escassa e a matéria orgânica do solo é mineralizada mais rapidamente. A colonização dos incultos pelo matorral mediterrâneo é mais lenta e apresenta uma selecção de espécies muito severa no sentido de privilegiar as plantas mais adaptadas ao stress hídrico e à heliofilia (Roxo, 1994).

Em consequência do incremento do stress hídrico durante uma estação seca mais longa e de mudanças significativas na reflectividade da superfície do solo durante o semestre quente, a aridez edáfica cresce no Alentejo (FERREIRA, 1995). As áreas constituídas pelos litossolos xistosos conhecem neste momento um défice hídrico do solo incompatível com a sobrevivência de um coberto vegetal contínuo e diversificado. A redução da reserva hídrica útil de $300 \mathrm{~mm}$, normalmente admitida para um solo profundo franco, para $25 \mathrm{~mm}$ (ou menos), induzida pela diminuição da espessura do mesmo solo e com a perda dos seus elementos finos num cenário de falta de chuva durante a Primavera, implica um emurchecimento precoce; ou seja, oito a dez semanas mais cedo do que na fase anterior à erosão (FERREIRA, 1999b). Nota-se também uma multiplicação de fases curtas de humidificação-dessecação ao longo do ciclo vegetativo, acelerada pela falta de sombra nos campos, que constitui um factor inibidor suplementar do crescimento e da produção de biomassa.

A produtividade das pastagens, a diminuição da densidade e da biodiversidade dos matos nos incultos e a mortalidade das azinheiras atingiram uma escala espacial tal, não só no Alentejo, mas em todo o Sudoeste da Peninsula Ibérica, que modificações nos intercâmbios de calor entre o solo e o ar tornaram-se sensíveis no semestre mais seco. Se tivermos em conta um balanço energético simplificado, as maiores mudanças incluem uma maior radiação solar directa absorvida pela superfície do solo, uma menor taxa de transferência de calor latente de evaporação e, em consequência, uma maior quantidade de energia solar disponível para a exportação de calor sensível, da superfície do solo para a baixa atmosfera (FERREIRA, 1995). O resultado que aponta para um aumento de calor sensível no ar à superfície é consistente com a tendência positiva actual das temperaturas diurnas estivais, maior no Alentejo do que no resto do País (SAntos et al., 2001). O número de dias com mais de $40^{\circ} \mathrm{C}$ aumentou também e as vagas de calor tornaram-se mais severas no Alentejo (GoMEs et al., 1996; FERREIRA, 1996). Mais altas temperaturas estivais nas áreas mais secas, onde a árvore desapareceu do sistema agrário de sequeiro, sugere um efeito directo da modificação ambiental sobre a aridificação do clima local e regional (FERREIRA et al., 2000). Esta hipótese, devidamente formulada a partir das modificações introduzidas no balanço energético regional entre a superfície terrestre e a atmosfera, deveria ser encarrada a sério na explicação do aquecimento do clima verificado em Portugal e no impacte da mudança de clima esperada no futuro. Nem todo o aquecimento verificado e a esperar no clima futuro se explicará pelo aumento do efeito de estufa antropogénico à escala global. A destruição do montado e o desaparecimento de uma reserva útil de água no solo em vastas áreas do Sudoeste ibérico, com o paradigma 
português situado no Alentejo interior, atingiu uma extensão suficiente (mais de $80000 \mathrm{~km}^{2}$ ) para podermos pensar numa modificação rápida do clima local e regional a partir da segunda parte do século $\mathrm{XX}$, e que sobrepõe agora os seus efeitos à tendência climática geral. Uma maior sensibilidade actual às secas e ao calor, uma maior aridez edáfica, uma protecção vegetal menor contra a erosão hídrica do solo, um aumento da frequência das cheias rápidas, apontam para uma dificil recuperação ambiental da paisagem do montado. Mesmo os montados feitos e maduros terão dificuldade em sobreviver num clima mais agressivo sem o suporte vital do solo no qual as árvores, algumas centenárias, tinham criado as suas raízes. Devemos assim concluir que, actualmente, os condicionalismos ambientais criados pela degradação do solo prevalecem sobre os factores de natureza socioeconómica na dinâmica da paisagem.

\section{CONCLUSÃO}

O sistema agrícola e a paisagem de montado que lhe estava associada foram profundamente alterados ao longo do século XX, respondendo essencialmente a um conjunto de determinismos históricos, os mais importantes dos quais foram referidos na figura 1. Os diferentes sistemas agrícolas que se sucederam no Alentejo ao longo do século XX foram determinantes para introduzir uma diversidade na paisagem, mas eles não tiveram em conta nem o equilíbrio nem a valorização ambiental do montado.

Os problemas de degradação ambiental e paisagística no sistema do montado resultam, quer da intensificação dos sistemas culturais e da mecanização das operações agrícolas num ambiente biofísico frágil, quer do próprio abandono destes sistemas culturais. A intensificação da intervenção humana no sistema do montado não se revestiu afinal de aspectos diferentes dos observados noutros sistemas agrícolas. Correspondeu a uma diminuição da biodiversidade e, em consequência disso, a uma diminuição da estabilidade da paisagem criada. No caso do Alentejo, o tamanho das parcelas ultrapassa em muito a escala da variação dos factores ecológicos, introduzindo um factor agravante de desequilíbrio no sistema agro-silvo-pastoril.

A evolução futura da paisagem de montado não ficará, tal como no passado, na dependência exclusiva de condicionalismos de políticas agrícolas e da conjuntura socioeconómica. O desequilíbrio ambiental criado com a intensificação do uso e a modificação da estrutura do montado é fonte de aridez edáfica que amplifica os efeitos ligados à aridez natural do clima regional e à variabilidade interanual da chuva. Foi nas áreas de substrato impermeável de xistos que o desaparecimento precoce do solo deixou as marcas de degradação ambiental mais acentuadas, ao ponto de tornar inviável a sobrevivência da árvore ou a sua reintrodução. Fora dessas áreas, e numa perspectiva mais ecológica que económica, a azinheira tem no montado um papel importante no ciclo de nutrientes e da água e assim na protecção e recuperação do solo. Neste sentido, 
num período de abrandamento da função agrícola, seria vantajoso do ponto de visto ambiental encontrar uma viabilidade para os montados já feitos, que apresentam ainda uma densidade de árvores aceitável.

\section{BIBLIOGRAFIA}

BrandÃo, C.; Fragoso, M. (1999) - Extreme storms and rainfall erosivity factor in Évora (Portugal), Zeitschrift für Geomorphologie, Supplement-Bd 115: 113-123.

Cabo Alonso, A. (1998) - Formación histórica de la dehesa, In C. G. Hernández Díaz-Ambrona editores, Jornadas de Agronomia «La Dehesa : aprovechamiento sostenible de los recursos naturales», Editorial Agrícola Español S. A., Madrid: 15-42.

FEIo, M. (1998) - A evolução da agricultura do Alentejo meridional, Colibri, Lisboa: 108 p.

Ferreira, D. DE Brum (1992)-Problemas florestais actuais no Alentejo, Finisterra-Revista Portuguesa de Geografia, XXVII (53), Lisboa: 25-62.

Ferreira, D. DE Brum (1995) - Evolution du stress hydrique de Printemps en Alentejo : répercussions sur l'environnement, Publications de l'Association Internationale de Climatologie, Vol. 7, Aix-en-Provence: 144-149.

Ferreira, D. De Brum (1996) - Les records de chaleur estivale en Péninsule Ibérique, Publications de l'Association Internationale de Climatologie, Vol. 9, Aix-en- Provence: 76-83.

Ferreira, D. DE Brum (1999a) - Os incultos na dinâmica e na valorização da paisagem do Alentejo, Desenvolvimento Rural: Desafio e Utopia, Estudos para o Planeamento Regional e Urbano n. ${ }^{\circ}$ 50, Centro de Estudos Geográficos, Lisboa: 235-242.

Ferreira, D. DE Brum (1999b) - Aridez, seca e aridificação. Impacte sobre o risco de desertificação no Alentejo, VIII Colóquio Ibérico de Geografia, Resumos, Universidade Nova, Lisboa:119.

Ferreira, D. DE Brum (2000) - Environmental impact of land use change in the inner Alentejo (Portugal) in the $20^{\text {th }}$ century, in Olav Slaymaker ed., Geomorphology and Human Activity: Their Role in Global Environmental Change, J. Wiley \& Sons, Chichester: 249-267.

Ferreira, D. De Brum; Fragoso, M., Gomes, P. (2000) - Climate change and man-induced vulnerability of environment, International Conference on Climate Change, Science, Economics and Politics, Fundação Calouste Gulbenkian, Lisboa, Painel 12.

Fragoso, M.; Gomes P. (2000)-Contribution à l'étude climatologique des épisodes de fortes précipitations dans le sud du Portugal (1983-1998), Publications de l'Association Internationale de Climatologie, Vol. 13, Aix-en-Provence: 110-119.

Gomes, P.; Ferreira, D. DE Brum (1996) - Les vagues de chaleur de juillet et août 1995 en Péninsule Ibérique, Publications de l'Association Internationale de Climatologie, Vol. 9, Aix-en-Provence: 109-116.

Maheras, P.; Alcoforado, M. J.; Guika, S.; Vafiadis, M. (1994)-Relations entre les périodes sèches et humides des précipitations et les indices de circulations atmosphériques au Portugal durant la dernière période séculaire, Publications de l'Association Internationale de Climatologie, 7, Aix-en-Provence: 241-248.

Mendes, J. Casimiro; Coelho, M. F. Santos (1993)-Variabilidade climática em Portugal continental. Quantidade de precipitação, Monografia de Meteorologia e Geofísica n. ${ }^{4}$ 43, I.N.M.G., Lisboa, $158 \mathrm{p}$. 
Natividade, J. V. (1950) - Subericultura, Ministerio de Agricultura, Lisboa; 327 p.

Rosas, F. (1994) - O Estado Novo (1926-1974), História de Portugal, Direcção de José Mattoso, Vol. 7, Editorial Estampa, Lisboa: 589 p.

Roxo, M. J. (1994) - A acção antrópica na degradação de solos. A Serra de Serpa e de Mértola, Tese de Doutoramento, Universidade Nova de Lisboa: 387 p.

Santos, F. Duarte; Forbes, K.; Moita, R. (editores, 2001)-Mudança Climática em Portugal, Cenários, Impactes e Medidas de Adaptação - SIAM , Sumário Executivo e Conclusões, Gradiva, Lisboa: 24 p.

Silbert, A. (1966) - Le Portugal Méditerranéen à la fin de l'Ancien Régime, XVIII'-Début XIXe siècle. Contribution à l'histoire agraire comparée, 2 volumes, École Pratique des Hautes Études, Paris: 1200 p. (Publicação pelo INIC da 2. ${ }^{a}$ edição, Lisboa, 1978, 3 volumes, 1214 p).

VIEIRA, J. N. (1991) - Arborização e desarborização em Portugal, Informação, 8, Direcção Geral das Florestas: 8-15.

Ventura, J. E. ( 1994) - As precipitações no Sul de Portugal, Tese de Doutoramento, Universidade Nova de Lisboa. 438 p. pol. 